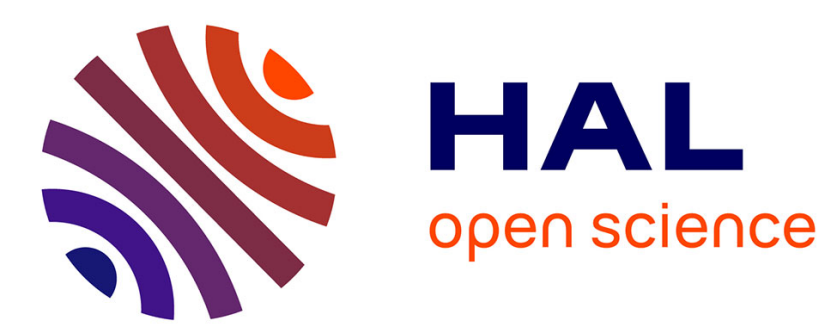

\title{
Micromechanisms of fracture and fatigue in Ti3Al based and TiAl based intermetallics
}

A. James, R. Chave, C. Hippsley, P. Bowen

\section{To cite this version:}

A. James, R. Chave, C. Hippsley, P. Bowen. Micromechanisms of fracture and fatigue in Ti3Al based and TiAl based intermetallics. Journal de Physique IV Proceedings, 1993, 03 (C7), pp.C7-411-C7-421. 10.1051/jp4:1993764 . jpa-00252184

\section{HAL Id: jpa-00252184 https://hal.science/jpa-00252184}

Submitted on 1 Jan 1993

HAL is a multi-disciplinary open access archive for the deposit and dissemination of scientific research documents, whether they are published or not. The documents may come from teaching and research institutions in France or abroad, or from public or private research centers.
L'archive ouverte pluridisciplinaire $\mathbf{H A L}$, est destinée au dépôt et à la diffusion de documents scientifiques de niveau recherche, publiés ou non, émanant des établissements d'enseignement et de recherche français ou étrangers, des laboratoires publics ou privés. 


\title{
Micromechanisms of fracture and fatigue in $\mathrm{Ti}_{3} \mathrm{Al}$ based and TiAl based intermetallics
}

\author{
A.W. JAMES (1), R.A. CHAVE, C.A. HIPPSLEY* and P. BOWEN \\ School of Metallurgy and Materials, IRC in Materials for High Performance Applications, The University \\ of Birmingham, England \\ * AEA Technology, Harwell, England
}

\begin{abstract}
Micromechanisms of fracture and fatigue crack growth resistance in specific Ti3Al based and TiAl based intermetallics are reviewed. Effects of test temprature, environment and microstructure on crack growth resistance are considered in detail for several Ti3Al and Ti'Al based intermetallic systems under development. The implications of these studies for the structural reliability of these materials is also addressed briefly,
\end{abstract}

1. Introduction

Over recent years much research effort has been directed towards the development of $\mathrm{Ti}_{3} \mathrm{Al}$ based and TiAl based intermetallics. Alloys in both classes of materials are now readily available commercially. Typical representative compositions of commercial interest are Ti-25Al-10Nb-3V-1Mo (at \%) "Super $\propto 2 "$ and $\mathrm{Ti}-48 \mathrm{Al}-2 \mathrm{Mn}-2 \mathrm{Cr}(\mathrm{at} \%)$ - for $\mathrm{Ti}_{3} \mathrm{Al}$ based and TiAl based aluminides respectively.

The impact of Ti3Al based materials on the aerospace sector has been limited to date. This is, in part due to the continued development of improved high temperature Ti alloys such as Ti-6 Al-4Sn-3.5Z $\mathrm{r}-0.7 \mathrm{Nb}$ $0.5 \mathrm{Mo}-0.35 \mathrm{Si}-0.05 \mathrm{C}(\mathrm{wt} \%)$ - IMI 834, and also because the Ti3Al based alloys possess limited oxidation (and fire) resistance at temperatures of $\geq 620^{\circ} \mathrm{C}$. Nevertheless, these alloys have met their original target properties in many instances, and in particular they may still find application at modest temperatures where their reduced density, high strength and increased modulus can still result in significant weight savings.

Attention has now been focussed increasingly towards TiAl based intermetallics. In principle, their application should encompass the temperature range from $600-800^{\circ} \mathrm{C}$ because they do possess good oxidation (and fire) resistance. At such temperatures the utilisation of both monolithic and fibre reinforced TiAl materials offers potential for marked weight savings compared with nickel based superalloys.

Both classes of materials possess limited ductility, relatively poor fracture toughness and relatively poor fatigue crack growth resistance particularly at room temperature. This paper reviews micromechanisms of crack growth under both monotonic and cyclic loading in specific examples of these materials at both room and elevated temperatures. The influence of microstructure, test temperature and environment (at elevated test temperatures) is highlighted.

\section{Micromechanisms of crack growth in Ti3 Al based intermetallics}

Ti3Al based materials, typically of compositions Ti-25Al-10Nb-3V-1Mo ("Superø2") and Ti-23-Al-9Nb$2 \mathrm{Mo}-0.9 \mathrm{Si}$ (at \%) can exhibit good strength at room temperature (tensile (fracture) strengths of upto 1400 MPa have been obtained for some compositions), and good strength retention to a temperature of $700^{\circ} \mathrm{C}$ (where tensile strength in excess of $850 \mathrm{MPa}$ has been obtained). Combined with improved modulus, and improved modulus retention at elevated temperatures compared with conventional titanium alloys, then such properties are attractive if the structural reliability of these alloys can be established (1).

(1)

now at Rolls Royce plc, Derby, England 
Unfortunately in such alloys tensile elongations to failure are usually $\leq 2 \%$ at room temperature, and even at elevated temperature they seldom exceed $7 \%$. Moreover, fracture toughness, $\mathrm{K}_{\mathrm{IC}}$, values for such compositions at room temperature are generally in the range from $12-18 \mathrm{MPam}^{1 / 2}$, although at test temperatures of $2500^{\circ} \mathrm{C}$ values in excess of $30 \mathrm{MPam}^{1 / 2}$ can be obtained routinely $(2,3,4)$. In addition, relatively steep fatigue crack growth resistance curves, da/dN versus $\Delta \mathrm{K}$ are obtained at room temperature (where da/dN is the crack increment per cycle and $\Delta K$ is the fatigue stress intensity factor range). In this context values of the Paris-Erdogan exponent, $m$, of between 5-8 are measured typically at room temperature $(3,5,6)$, for stage II fatigue crack growth, where $m$ is defined by

$$
\mathrm{da} / \mathrm{dN}=\mathrm{A} \Delta \mathrm{K}^{\mathrm{m}}
$$

and $A, m$ are materials dependent constants

The reasons for this limited crack growth resistance under both monotonic and cyclic loading in such alloys is now considered. Typical microstructures that may arise (after ageing) in these materials are shown in Figure 1 (a)-(c). Note the finer transformed matrix shown for an $\alpha_{2} / \beta$ heat-treated condition in Figure 1(a) for "Super $\propto 2$ ". For the development material of base composition Ti-23Al-11Nb-0.9Si a coarser scale of transformed matrix is obtained here, see Figure 1 (b) and (c). If material is $\beta$ processed prior to heat-treatment below the $\beta$ transus, primary $\alpha_{2}$ precipitates in the form of large laths, Figure $1(b)$,rather than as the equiaxed $\propto 2$ regions that are more commonly found on $\propto 2 / \beta$ heat-treatment after $\propto 2 / \beta$ processing, see Figure 1(a). Heat treatment above the $\beta$ transus (after $\beta$ processing) on transformation results in the basket-weave microstructure shown in Figure 1(c). Since identification of failure micromechanisms is facilitated in coarser-scale microstructures attention is now focussed on such microstructures primarily.

\subsection{Fracture and fatigue crack growth at room temperature}

In the base alloy Ti-23Al-11 Nb-0.9Si, uniequivocal evidence of the transgranular cleavage of individual $\propto 2$ laths (of 1-2 $\mu \mathrm{m}$ in thickness has been obtained under conditions of fast fracture, Figure 2(a), and during sub-critical fatigue crack growth, Figure $2(\mathrm{~b})$, for both $\propto_{2} / \beta$ and $\beta$ heat-treated microstructures. For these conditions, the critical nature of retained $\beta$ regions in arresting and deflecting propagating cracks has also been identified (2,5-8). An example produced under cyclic loading is given in Figure 2(c), where crack deflection by the lighter (retained $\beta$ ) phase is illustrated on a combined metallographic/fractographic section. A modified Griffith criterion can be used to suggest that the failure of an individual $\propto 2$ lath is indeed consistent with the observed tensile fracture stress of these microstructures and appears to define the micromechanism of failure under monotonic loading (2). Similarly, a micromechanism for crack growth under cyclic loading involving sub-critical cleavage fracture has been proposed $(5-8)$. It involves discrete cleavage across $\propto 2$ laths and arrest at the retained $\beta$ phase, consistent both with the observed crack growth rates, (5-8) and the high " $m$ ", values measured. However, care is required in detail, because the amount, thickness and distribution of the retained $\beta$ phase also appears to be critical. This can be deducted from Figure 3 , where the microstructure containing coarser primary $\propto 2$ laths, Figure $2(\mathrm{~b})$, actually posesses slightly increased fatigue crack growth resistance at room temperature. (Further work has shown that the area fraction of retained $\beta$ phase is also increased for this microstructure ${ }^{(8)}$ ). Moreover, the addition of $2 \mathrm{Mo}($ at $\%)$ to this alloy refines the transformed matrix, yet the fracture toughness decreases slightly (from $15 \mathrm{MPam}^{1 / 2}$ for the base alloy to $13 \mathrm{MPam}^{1 / 2}$ for the Mo modified alloy) and no improvement in fatigue crack growth resistance is observed, Figure 3 . Most important, fractographic observations Figure 2(d) for the Mo containing alloy (Ti-23Al-9Nb-2Mo-0.9Si (at \%)) indicate that the critical failure event is now the fracture of a group or packet of $\propto 2$ laths, and hence a larger critical microcrack unit size can be produced and is consistent with the reduced fracture toughness measured. These observations serve to illustrate the potential complexity of crack advance in such alloys, but they do identify the controlling micromechanism of transgranular cleavage at room temperature.

\section{$2.2 \quad$ Fracture and Fatigue crack growth at elevated temperature}

At elevated temperatures of $2500^{\circ} \mathrm{C}$, the failure mode of the base alloy Ti-23Al-11 Nb-0.9Si (at \%) changes to ductile microvoid coalescence (2), Figure $4(\mathrm{a})$. At the test temperature of $600^{\circ} \mathrm{C}$ fatigue striations are observed clearly $(5,6-8)$, Figure $4(\mathrm{~b})$, and are indicative of a classical reverse-plasticity based mechanism of crack advance under cyclic loading. Nominal fracture toughness values of $\geq 30 \mathrm{MPam}^{1 / 2}$ are measured for a wide range of microstructures and also for the higher strength $\alpha_{2}$ based alloys of similar compositions. Note that in such higher strength alloys the cleavage of $\alpha_{2}$ precipitates can persist to a test temperature of $700^{\circ} \mathrm{C}$, and $\beta$ heat-treated microstructures can fail by ductile integranular fracture (4). Care must be taken therefore in defining a "ductile-brittle transition" but increased fracture toughness values are obtained at such elevated temperatures for all conditions. Under cyclic loading, fatigue crack growth resistance curves are simitar for a wide range of microstructures, Figure 3, and for higher strength conditions. Exponent " $\mathrm{m}$ " values of 1.4-2.0 are obtained. At elevated 
test temperatures of $\geq 600^{\circ} \mathrm{C}$, effects of environment are observed even at a cyclic frequency of $20 \mathrm{~Hz}$, see Figure 5 (for a Ti-23Al-9Nb-2Mo-1 $\mathrm{Zr}-1.2 \mathrm{Si}\left(\mathrm{at} \%\right.$ ) alloy $(6)$ tested at $700^{\circ} \mathrm{C}$ ), where crack growth rates in air for $\triangle \mathrm{K} \leq 12 \mathrm{MPam}{ }^{1 / 2}$ are faster than those in vacuum $\left(\leq 1,10^{-5} \mathrm{mbar}\right)$. Elsewhere, effects of cyclic frequency have also been observed (3) and these have been attributed to the ingress of external oxygent to crack-tip regions.

In summary, the influence of microstructure on fracture toughess and fatigue crack growth resistance appears to be relatively modest and isobserved at room temperature only for the alloy compositions considered here. This would suggest that marked improvement in crack growth resistance will require radical changes in alloy composition. Nevertheless, many questions of a fundamental nature persist, and further work is ongoing to identify the micromechanisms of crack advance more precisely.

\section{Micromechanisms of crack growth in TiAl based intermetallics}

Two phase TiAl intermetallics, of compositions such as Ti-48Al-2Mn-2Nb (at\%) can exhibit high modulus ( $\mathrm{\equiv} \cong 165 \mathrm{GPa}$ ) and moderate strength (tensile (fracture) strengths of 250-600 MPa) at room temperature. In addition they offer good retention of these properties to elevated temperatures of $\leq 700^{\circ} \mathrm{C}$, and combined with their low density $(\rho \sim 4,000 \mathrm{kgm}-3)$ this suggests potential use in structural applications. However, over this temperature range they exhibit ductilities of $\leq 3 \%$ and fracture toughness values $\leq 30$ $\mathrm{MPam}^{1 / 2}(9,10,11)$. Moreover, these properties vary widely with microstructure for a single alloy composition. For example, fracture toughness values can vary from 8 to $30 \mathrm{MPam}^{1 / 2}$, and Paris-Erdogan exponents, " $\mathrm{m}$ " values, under cyclic loading can vary between 6 and 60 (12). Many other authors have addressed the use of thermo-mechanical processing to control microstructure, and hence properties (13). Here, as-cast microstructures and as-cast plus heat-treated microstructures only are considered for alloy compositions of $\mathrm{Ti}-48 \mathrm{Al}(\mathrm{at} \%)$ and $\mathrm{Ti}-48 \mathrm{Al}-2 \mathrm{Mn}-2 \mathrm{Nb}(\mathrm{at} \%)$. Both alloys were produced by plasma-melting within the IRC at Birmingham and have an oxygen level of $650-700 \mathrm{ppm}$. The micromechanisms of fracture and fatigue crack growth in these alloys are found to be independent of test temperature to temperatures of upto $800^{\circ} \mathrm{C}$.

\subsection{Fracture and fatigue crack growth of as-cast microstructures}

For both alloys, the as-cast ingots (of nominal size of $100 \mathrm{~mm}$ diameter and $640 \mathrm{~mm}$ length) possess a near fully lamellar microstructure Figures $6(\mathrm{~b})$. A longitudinal macrosection of one of these ingots is shown in Figure 6(a). Within the large elongated grains of approximately $360 \mu \mathrm{m}$, lamellar plates are formed, in an orientation perpendicular to the length of these individual grains, Figure 6(b). Thus the majority of individual grains had lamellae arranged in a similar orientation and by carefully machining testpieces from the ingot it was possible to change the crack growth direction relative to the majority of the lamellar plates, see Figure 7. The resulting fracture toughness values and fatigue crack growth resistance varied markedly with testpiece orientation $(10,14)$. Fracture toughness values of between 20 and $24 \mathrm{MPam}^{1 / 2}$ were obtained for transverse testpiece orientations (see figure 7) but values of 12 $\mathrm{MPam}^{1 / 2}$ were obtained for longitudinal testpiece orientations (see Figure 7 ). In a similar manner, fatigue crack growth resistance was also dependent on testpiece orientation, Figure 8 . Values of the exponent $\mathrm{m}$, equation (1), were calculated to be 6,9 and 28 for the transverse, transverse off-centre, and longitudinal testpiece orientations respectively (15). Fractographic observations explain such crack growth resistance trends clearly, see Figure 9 , under both monotonic and cyclic loading. The lamellar plates appear to be relatively weakly bonded, and their interfaces can fail and either impede crack growth Figure 9 (a), (b), (c), (translamellar crack growth) or promote crack growth Figure 9(d), (interlamellar crack growth).

No evidence of ductile failure mechanisms are observed at test temperatures of $\leq 800^{\circ} \mathrm{C}$, and the micromechanism of fracture appears in all cases to be transgranular cleavage of the plates. In the compositions under consideration here, the majority of the lamellar plates are TiAl $(\gamma)$ and the interfaces are of the $\gamma / \gamma$ type although some $\gamma / \alpha_{2}$ interfaces have also been observed. Experiments to date on testpieces fractured and analysed inside a Scanning Auger Microscope (SAM) have proved inconclusive in distinguishing whether the fracture path is between $\propto 2 / \gamma$ or $\gamma / \gamma$ type interfaces (15). However, observations on a high resolution field emission gan (FEG) scanning electron microscopy operated in back scattered imaging mode have qualitatively confirmed that both $\gamma / \gamma$ and $\gamma / \alpha_{2}$ plate interfaces can fail (15). In these present alloys, it appears that the majority of interfaces that fail are of the $\gamma / \gamma$ type. Ongoing studies are addressing this issue, but it is of an academic nature only because such anisotropic crack growth resistance will be unacceptable for most engineering components. If fully lamellar microstructures are to be used in practice it is essential that these well aligned packets of lamellar plates are limited to as small a size as possibie and orientated randomly throughout the material, to achieve acceplable crack growth resistance. In this context, as-cast XD materials may be of interest, but is is 
unlikely that their crack growth resistance will be as good as that of the optimised orientations shown in Figure 8. For the as-cast condition tested in an optimised orientation at $700^{\circ} \mathrm{C}$, there are also effects of environment on fatigue crack growth resistance, see Figure 10. Crack growth rates are faster in air by one order of magnitude typically, even at a cyclic frequency of $10 \mathrm{~Hz}$. The mechanism of environmental attack is as yet unclear, and further work is ongoing to address such features.

\subsection{Effects on microstructure on crack growth resistance}

Heat-treatments following casting have been carried out to simulate the possible hot-isostatic pressing temperature of $1200^{\circ} \mathrm{C}$. At this test temperature, and for the $\mathrm{Ti}-48 \mathrm{Al}-2 \mathrm{Mn}-2 \mathrm{Nb}(\mathrm{at} \%)$ composition studied here, the growth of equiaxed and twin related $\gamma$ grains is rapid. Hold - times of 0.5, 2 and 12 hrs develop a duplex microstructure, a near fully $\gamma$ microstructure (of grain size $86 \mu \mathrm{m}$ ) and a fully $\gamma$ microstructure (of grain size $124 \mu \mathrm{m}$ ) respectively. The duplex microstructure and the large grain size fully $\gamma$ microstructure are shown in Figure 11(a) and (b) respectively. Marked effects of microstructure on fracture toughness and fatigue crack growth resistance are observed. Fracture toughness values for the fully $\gamma$ conditions vary between 8 and $12 \mathrm{MPam}^{1 / 2}$. Fatigue crack growth resistance curves for tests performed at $800^{\circ} \mathrm{C}$ are shown in Figure 12. Clearly, the presence of gamma grains degrades crack growth resistance : measured values of the exponent "m", are 6, 14, 23 and 56, for "fully" lamellar, duplex, fully gamma (grain size $86 \mu \mathrm{m}$ ) and fully gamma (grain size $124 \mu \mathrm{m}$ ) microstructures respectively $(12,15)$. Fractographic observations indicate at test temperatures of $\geq 500^{\circ} \mathrm{C}$ that $\gamma$ grains fail by brittle intergranular decohesion, under both fatigue and fast fracture conditions, see Figure 13(a) and (b) respectively. The introduction of such static failure modes during fatigue will be expected to increase crack growth rates markedly, and both a large microcrack size and weak failure path is introduced into a fracture toughness testpiece. At test temperatures of $\leq 500^{\circ} \mathrm{C}$, the equiaxed $\gamma$ grains fail by transgranular cleavage rather than by brittle intergranular decohesion but this alternative failure mode also reduces crack growth resistance dramatically. The mechanism of this transgranular - intergranular transition of $\gamma$ grains is not yet fully understood, but both failure modes reduce the crack growth resistance to unacceptable levels. In all cases, micromechanisms of fracture are qualitatively similar under both cyclic loading and fast fracture conditions and underline the brittle crack growth mechanisms that predominate in these TiAl based materials. To achieve acceptable fatigue crack growth resistance near fully lamellar microstructures would appear to be necessary, and the size of the lamellar colonies will have to be minimised if the component is to be used under multi-axial loading.

\section{General Discussion}

Compared with conventional engineering alloys both TizAl based and TiAl based intermetallics possess poor fracture toughness and/or poor fatigue crack growth resistance. Both systems are intrinsically brittle in pre-cracked testpieces when tested at room temperature, and brittle failure mechanisms may persist in TiAl based materials to a temperature of $800^{\circ} \mathrm{C}$. This latter system would appear therefore to present the more significant problems in achieving structural reliability. Indeed, although reasonable fatigue crack growth resistance can perhaps be achieved for an optimised orientation even at room temperature, see Figure 14, great care is required since this crack growth resistance is highly anisotropic, Figure 8. Nevertheless, in Figure 14, this condition is seen to offer promise compared with TizAl alloys and conventional alloys such as IMI834. One attractive feature of the TiAl based alloys may also be their apparently high fatigue crack growth thresholds that may be deduced from Figures $8,10,12$ and 14 . By implication, their crack initiation resistance may therefore be promising and further work is addressing such an approach to the use of TiAl based intermetallics. In any event, the lifing of components which utilise materials with steep crack growth resistance curves i.e. $m>6$ is difficult unless the applied stresses in service are known accurately, because the increase in crack growth rate, da/dN, for a given crack increment, da, becomes extremely sensitive to this global applied stress. For such reasons it is unclear if monolithic TiAl based alloys have potential for use as discs and/or blades in gas turbine engines in the near future. Progress is likely to result from thermo-mechanical processing and careful compositional control to achieve microstructures in which brittle microcrack unit sizes are minimised.

\section{Conclusions}

Micromechanisms of crack growth resistance under monotonic and cyclic loading have been characterised for specific Ti3Al based and TiAl based intermetallics systems that are under development.

For $\mathrm{Ti}_{3} \mathrm{Al}$ based intermetallics tested at room temperature, failure is characterised either by the transgranular cleavage of individual $\alpha_{2}$ laths or by the transgranular cleavage of packets of laths. In some systems the controlling role of the retained $\beta$ phase has been highlighted under both monotonic and cyclic loading. At elevated temperatures of $\geq 500^{\circ} \mathrm{C}$, ductile microvoid coalescence is seen under fast fracture conditions, and evidence of crack advance by reversed cyclic plasticity can be observed under fatigue loading. 
For TiAl based intermetallics based on Ti-48AI-2Mn-2Nb(at \%) brittle micromechanisms of fracture predominate at test temperatures of upto $800^{\circ} \mathrm{C}$ under both montonic and cyclic loading. Marked effects of testpiece orientation on crack growth resistance are observed in as-cast (fully lamellar) microstructures and acceptable crack growth resistance is obtained only when the crack is forced to propagate across the lamellar plates (trans-lamellar fracture). Significant effects of microstructure on crack growth resistance are also seen. Equiaxed gamma grains provide easy crack paths by brittle integranular decohesion at test temperatures of $\geq 500^{\circ} \mathrm{C}$, and this results in low fracture toughness and extremely poor fatigue crack growth resistance. Therefore fully lamellar microstructures alone appear to offer potential for developing acceptable fatigue crack growth resistance.

\section{Acknowledgements}

In the course of this work two of the authors AWJ and RAC have been supported by SERC CASE awards with AEA Technology, Harwell and DRA, Aerospace Division, Farnborough respectively. The involvement of Dr S Kerry at DRA has been particularly beneficical to the study. Contributions to this paper from R J T Penton and XWu are also gratefully acknowledged.

\section{References}

1. H.A. Lipsitt, "Temperature Ordered Intermetallic Alloys", eds. C.C. Koch et al, MRS, Pittsburgh, PA, 1985, pp.351-364.

2. R.A. Chave, S. Kerry, C.J. Beevers and P. Bowen, Proc. 7th World Conference on Titanium, San Diego, July 1992, awaiting publication.

3. R.J.T. Penton, M.T. Cope and P. Bowen, Mat. Sci. Eng., A153, 1992, pp.508-513.

4. R.J.T. Penton, Ph.D. Thesis, The University of Birmingham, 1993.

5. R.A. Chave, C.J. Beevers and P. Bowen, Proc. 7th World Conference on Titanium, San Diego, July 1992, awaiting publication.

6. X. Wu and P. Bowen, Fatigue '93, Montreal, may 1993, eds. J.P. Bailon and I. Dickson, Vol. 2, pp.1013-1018, EMAS publications.

7. R.A. Chave, C.J. Beevers and P. Bowen, Fatigue '93, Montreal, May 1993, eds. J.P. Bailon and I. Dickson, Vol. 2, pp.1007-1012, EMAS publications.

8. R.A. Chave, Ph.D. Thesis, The University of Birmingham, 1993.

9. N.J. Rogers and P. Bowen, Euromat 91, Cambridge, July 1991, eds. T.W. Clyne and P.J. Withers, Vol. 2, pp.410-417, Institute of Materials.

10. A.W. James and P. Bowen, Proc. 7th World Conference on Titanium, San Diego, July 1992, awaiting publication.

11. N.J. Rogers, Ph.D. Thesis, The University of Birmingham, 1993.

12. A.W. James and P. Bowen, Mat. Sci. Eng., A153, 1992, pp.486-492.

13. Y.W. Kim, Acta Metall et Mater., 40, (6), 1992, pp.1121-1134.

14. A.W. James and P. Bowen, Proc. The Processing, Properties and Applications of Metallic and Ceramic Materials, Birmingham, September, 1992, eds. M.H. Loretto and C.J. Beevers, Vol. 2, pp.67-682, MCE publications.

15. A.W. James, Ph.D. Thesis, The University of Birmingham, 1993. 

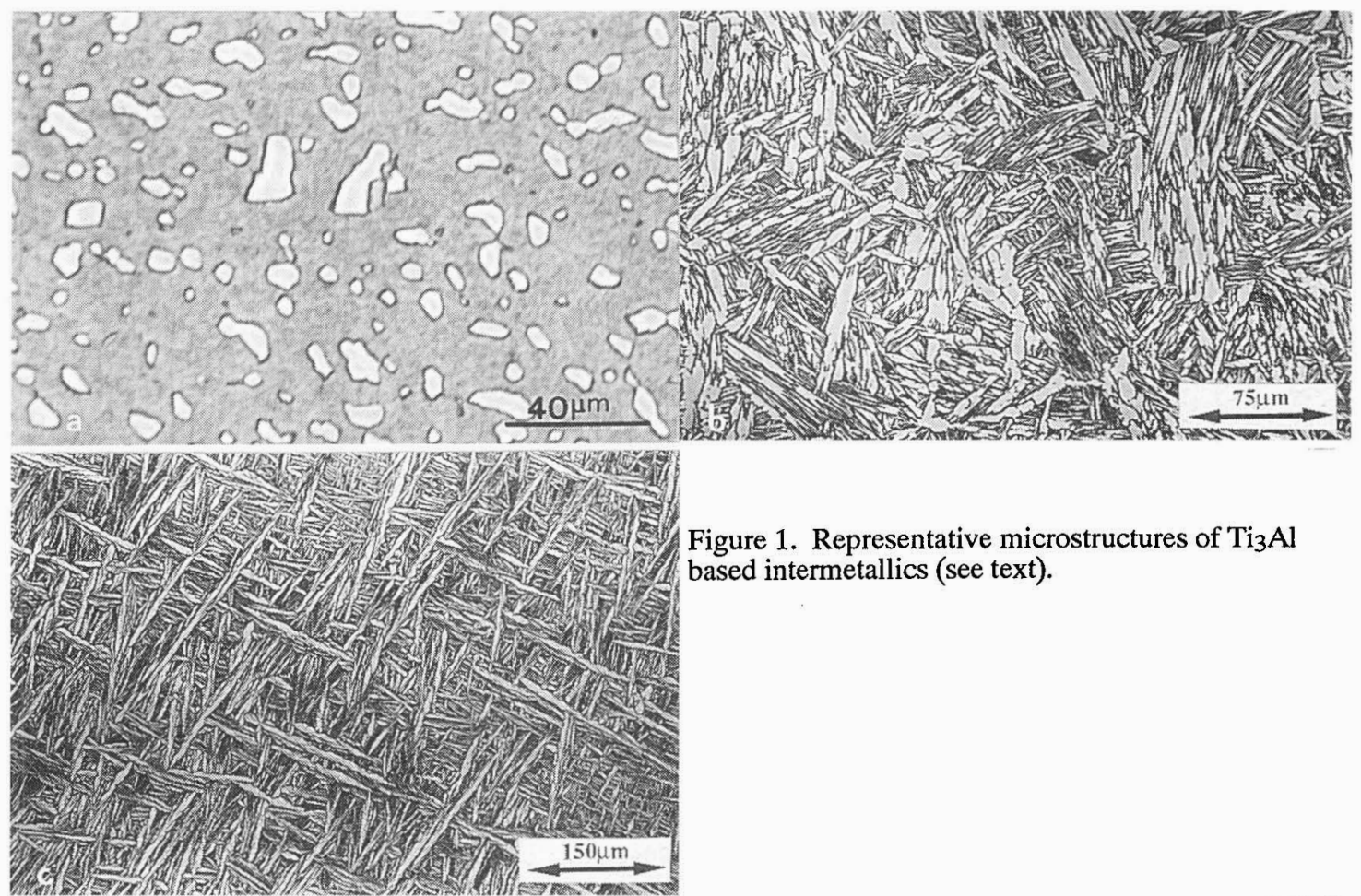

Figure 1. Representative microstructures of $\mathrm{Ti}_{3} \mathrm{Al}$

based intermetallics (see text).

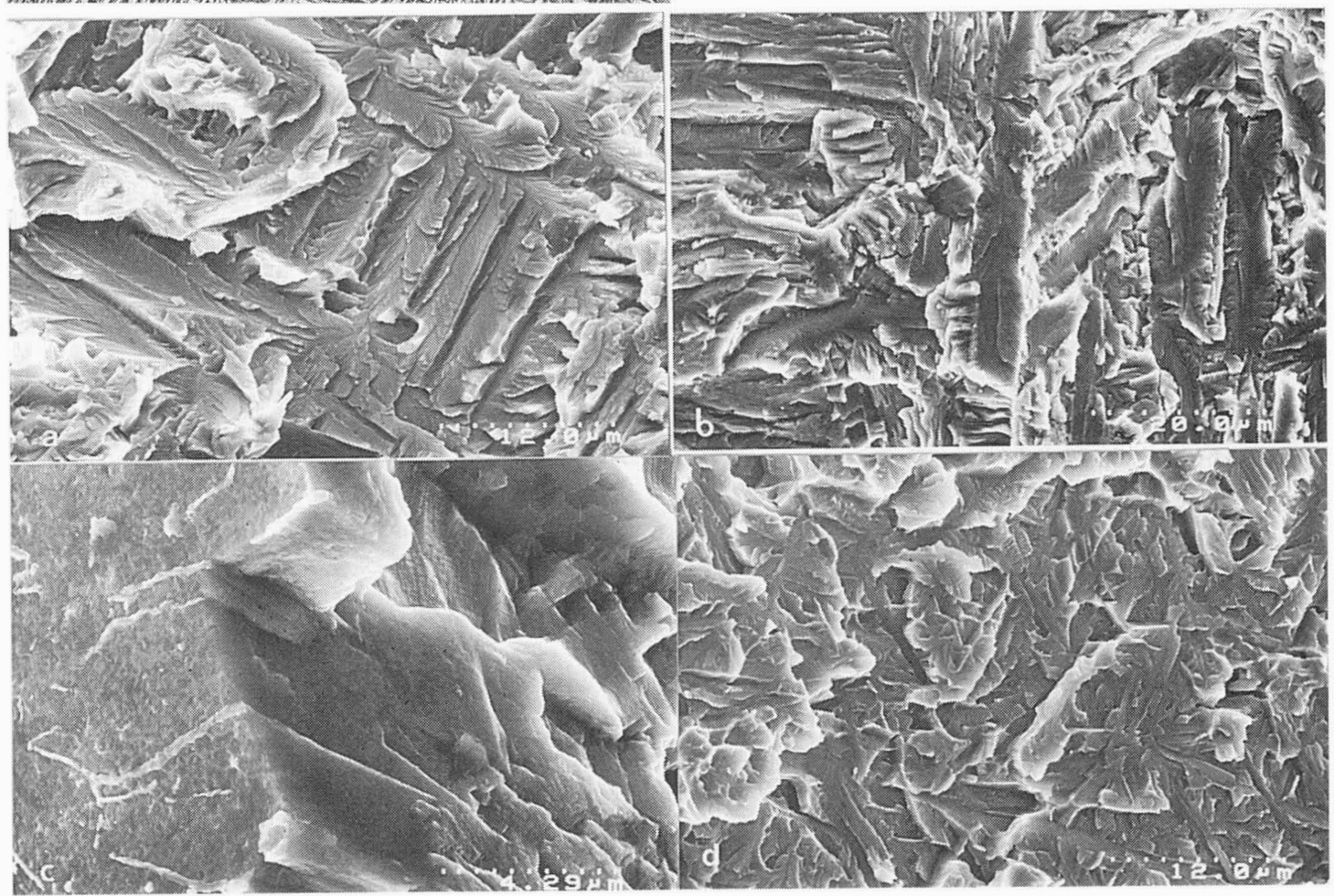

Figure 2. Fractographs produced under conditions of: (a),(d) fast fracture; (b),(c) fatigue at room temperature. $\mathrm{Ti}_{3} \mathrm{Al}$ based intermetallics (see text). 


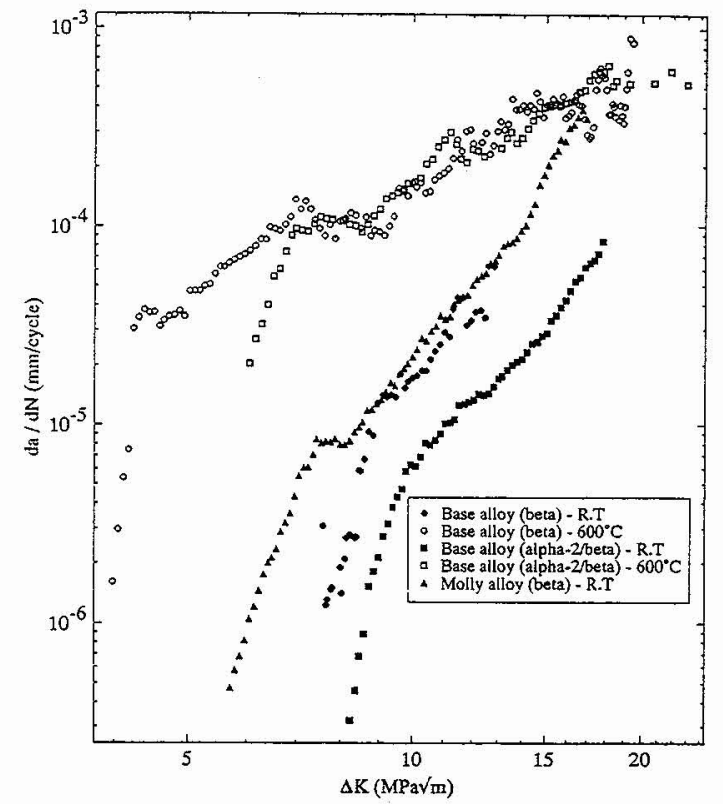

Figure 3. Fatigue crack growth resistance curves $\mathrm{da} / \mathrm{dN}$ versus $\Delta \mathrm{K}$. Ti ${ }_{3} \mathrm{Al}$ based intermetallics (see text)

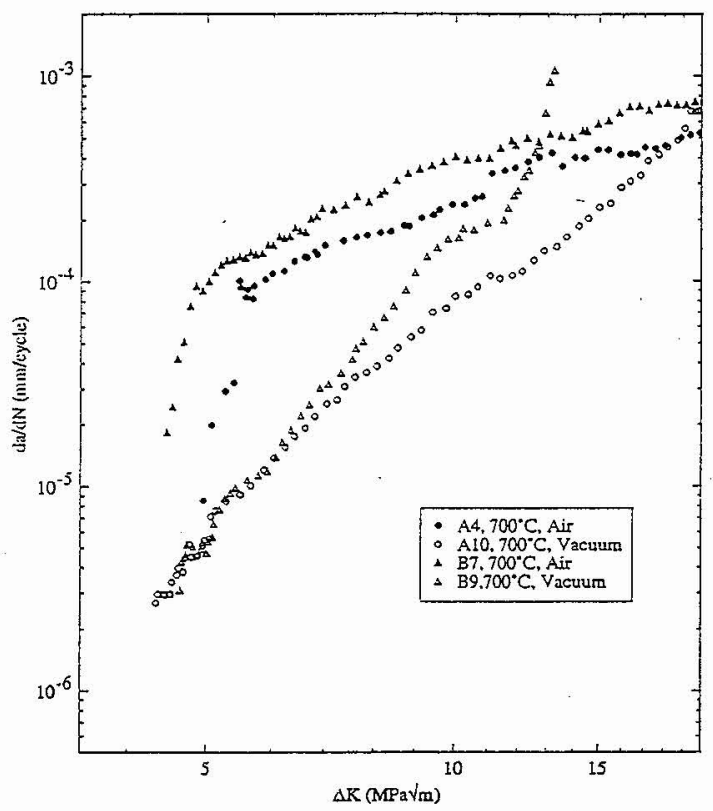

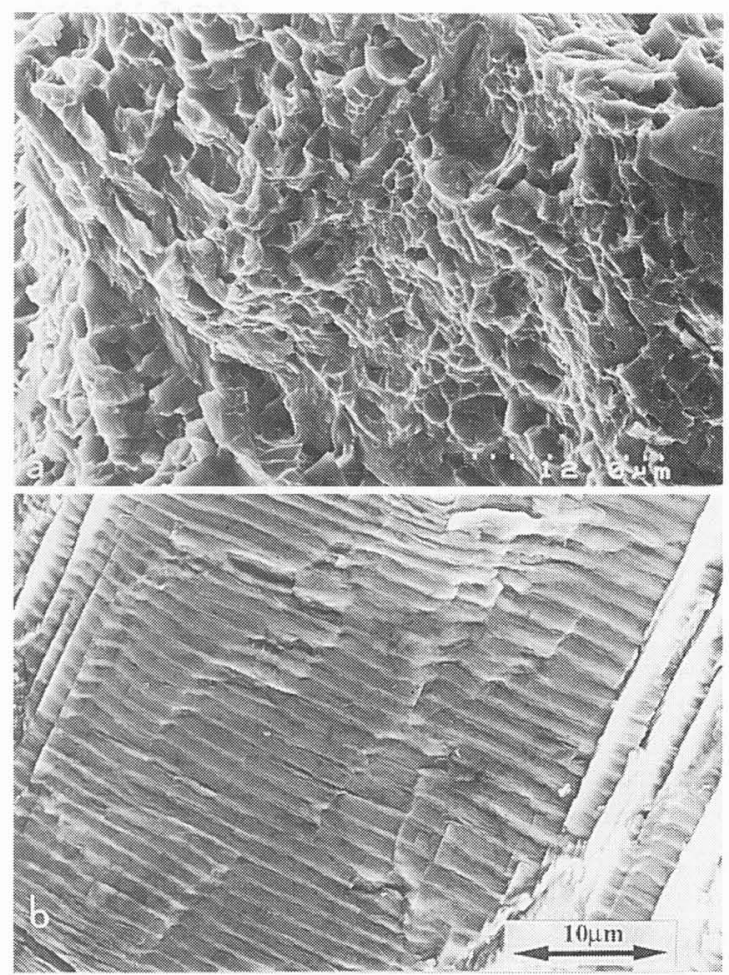

Figure 4. Fractographs produced under conditions of: (a) fast fracture, $500^{\circ} \mathrm{C}$; (b) fatigue, $600^{\circ} \mathrm{C}$. Ti$23 \mathrm{Al}-11 \mathrm{Nb}-0 \cdot 9 \mathrm{Si}(\mathrm{at} \%)$ - see text.

Figure 5. Effect of environment on fatigue crack growth resistance at $700^{\circ} \mathrm{C}, v=20 \mathrm{~Hz}$. Ti-23Al-9Nb$2 \mathrm{Mo}-1 \mathrm{Zr}-1 \cdot 2 \mathrm{Si}$ (at\%) - see text. 


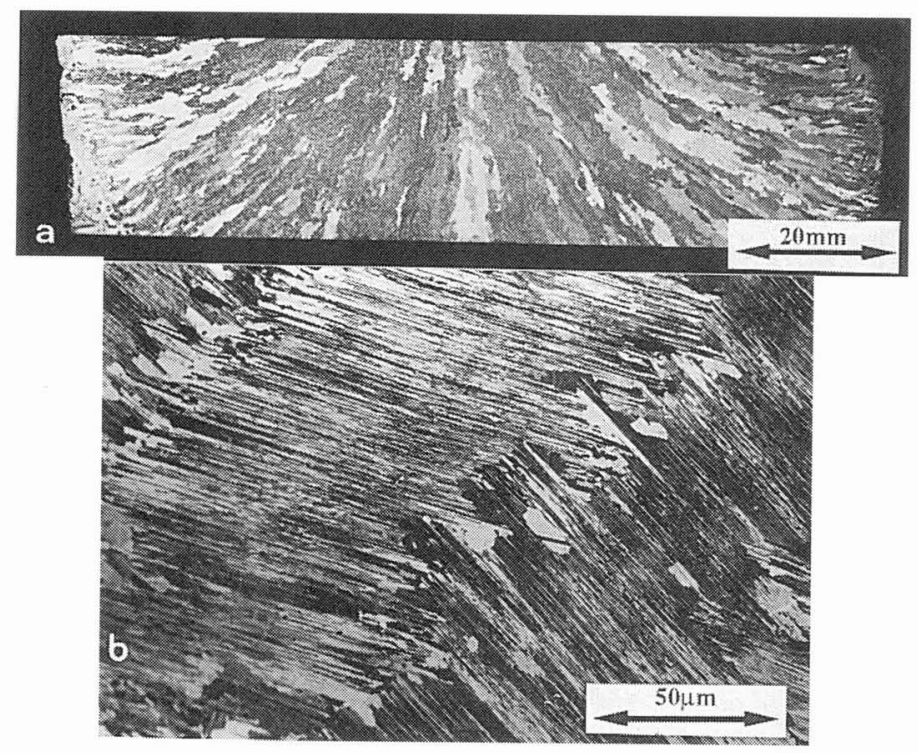

Figure 6. (a) Longitudinal macro structure Ti-48Al-2Mn-2Nb (at\%), (b) lamellar orientation within one grain.

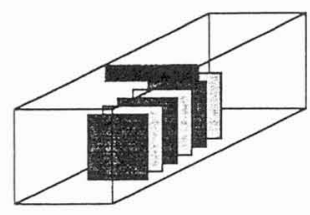

(a)

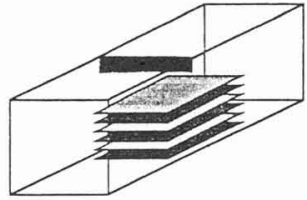

(b)

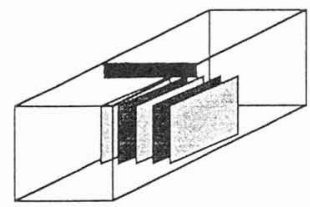

(c)

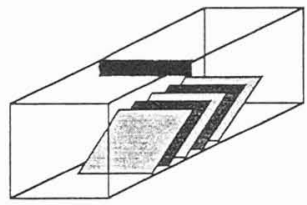

Figure 7. Orientation of lamellar plates within test pieces: (a) longitudinally - taken centrally from the ingot; (b),(c) transverse - centre of ingot; and (d) transverse "off centre".

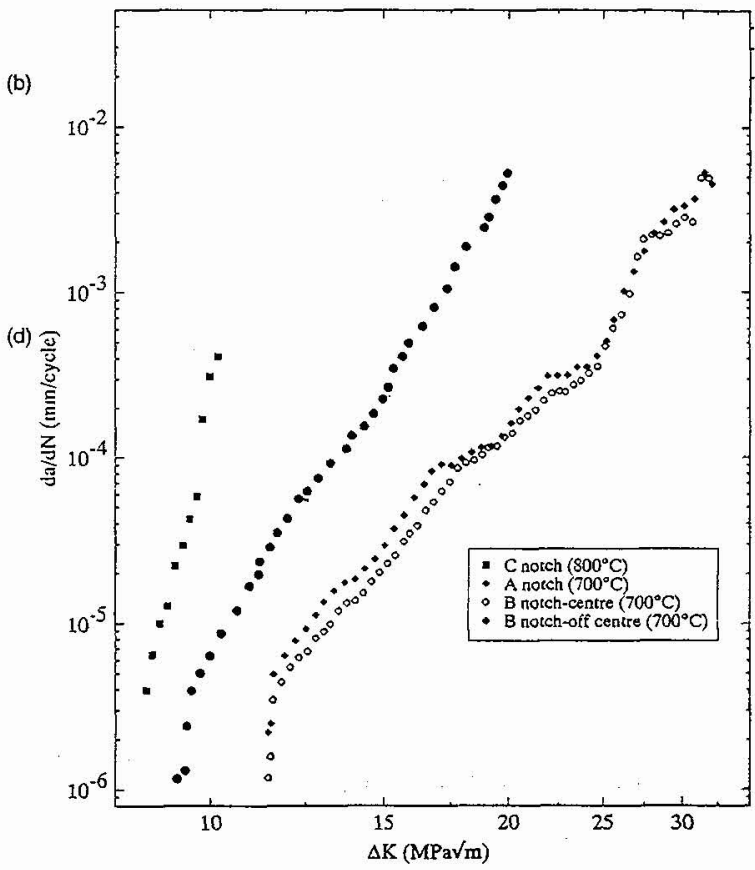

Figure 8. Fatigue crack growth resistance curve: $\mathrm{da} / \mathrm{dN}$ versus $\Delta \mathrm{K}$. Effects of testpiece orientation, in vacuum. Ti-48Al (at\%). 

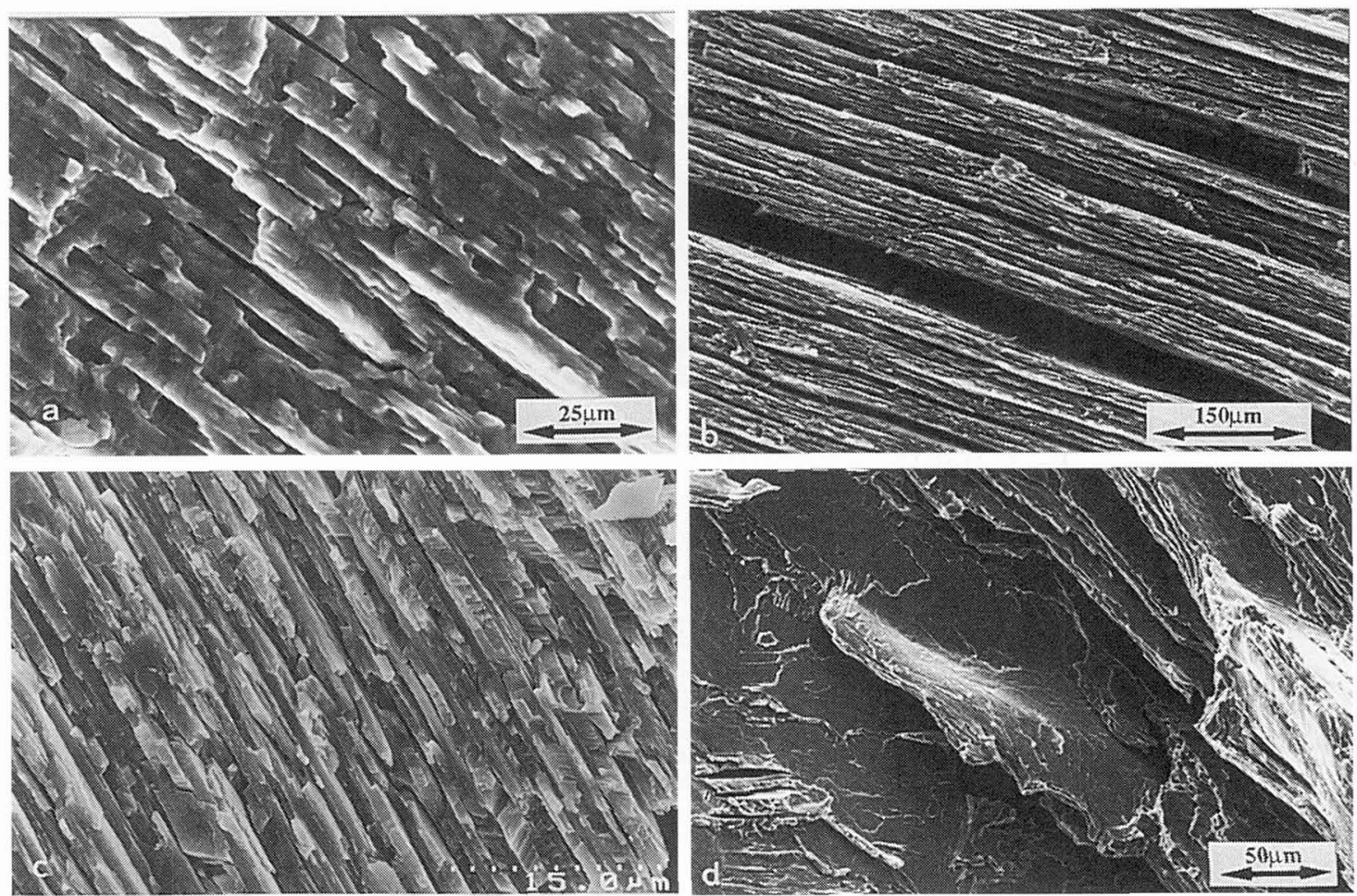

Figure 9. Fractographs: (a) fatigue (high $\Delta \mathrm{K}$ ), $700^{\circ} \mathrm{C}$, vacuum; (b) fracture, $700^{\circ} \mathrm{C}$, vacuum; (c),(d) fracture, room temperature. Ti-48Al - as cast.

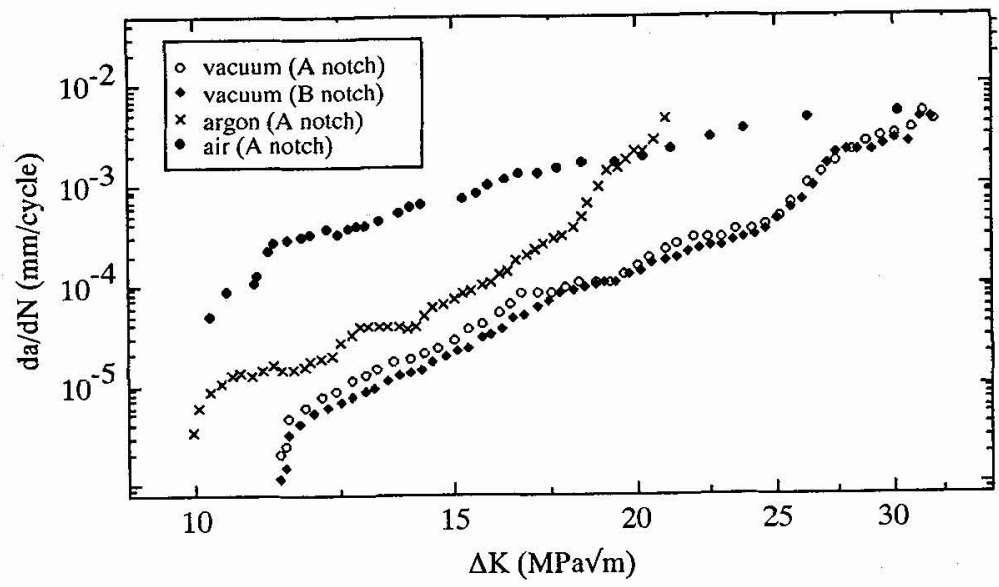

Figure 10. Effects of environment on fatigue crack growth resistance (optimised orientations) at $700^{\circ} \mathrm{C}$. 


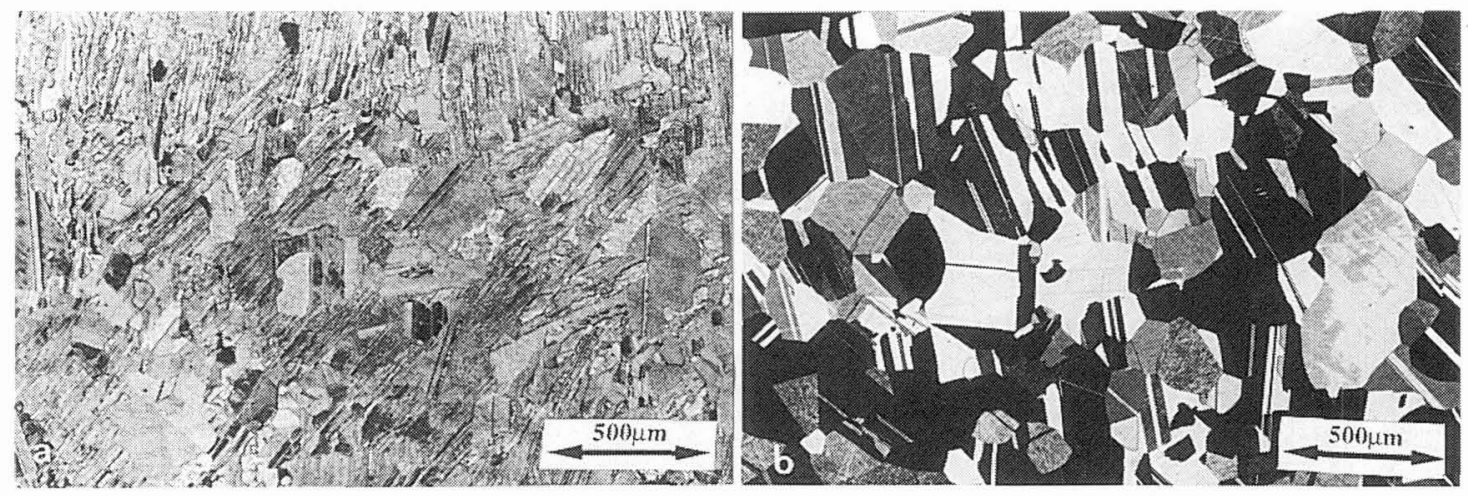

Figure 11. (a) Duplex microstructure, (b) fully gamma microstructure. Ti-48Al-2Mn-2Nb (at\%).

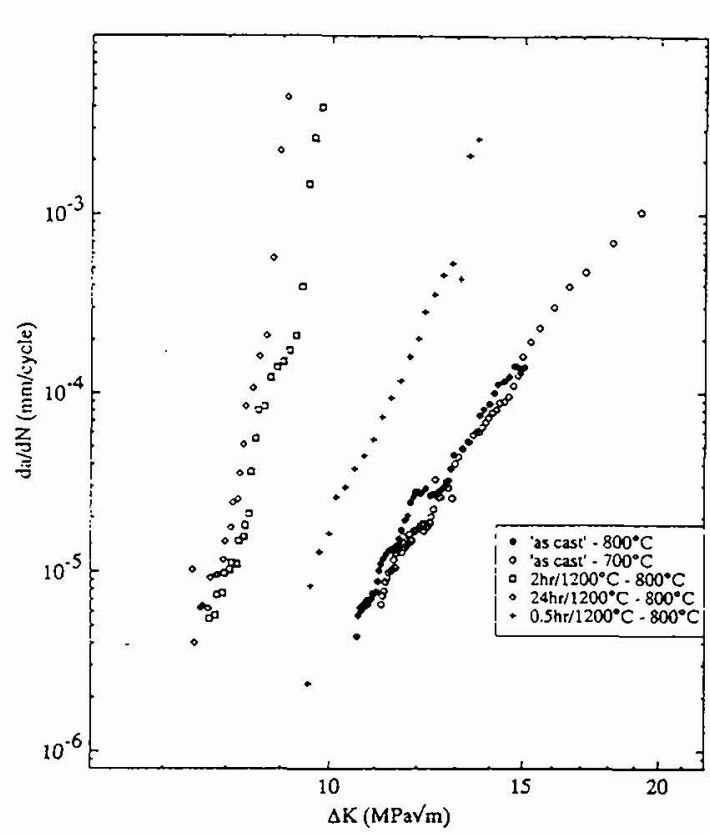

Figure 12. Fatigue crack growth resistance curve: $\mathrm{da} / \mathrm{dN}$ versus $\Delta \mathrm{K}$, vacuum. $\mathrm{Ti}-48 \mathrm{Al}-2 \mathrm{Mn}-2 \mathrm{Nb}$ (at\%).

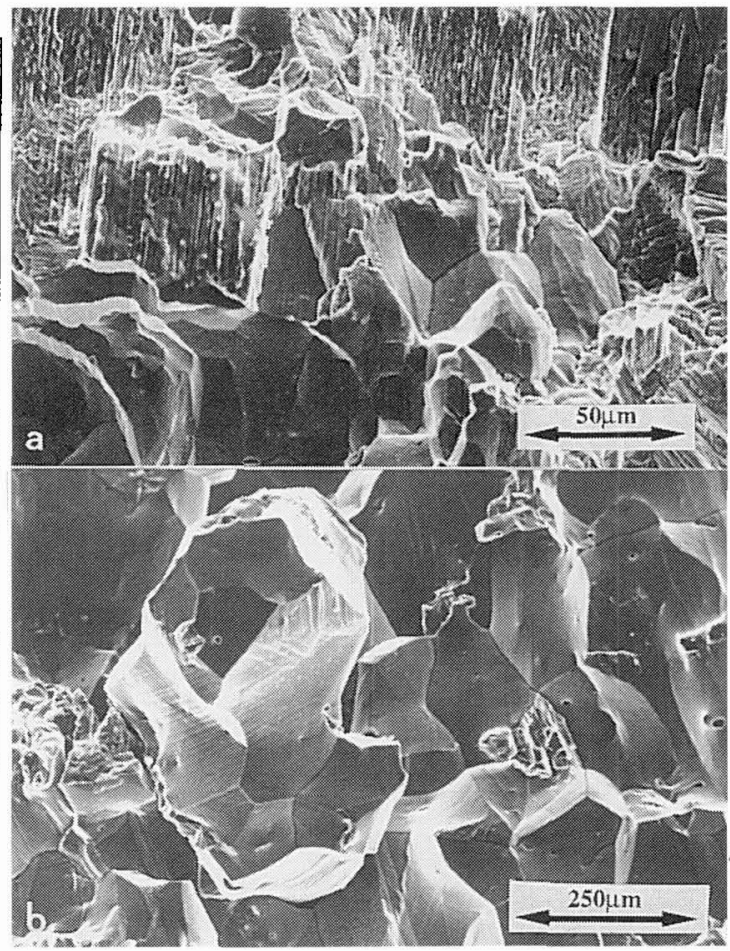

Figure 13. Fractographs: (a) duplex microstructure, fatigue; (b) gamma microstructure, fracture. Ti-48Al$2 \mathrm{Mn}-2 \mathrm{Nb}(\mathrm{at} \%)$ tested at $800^{\circ} \mathrm{C}$, vacuum. 


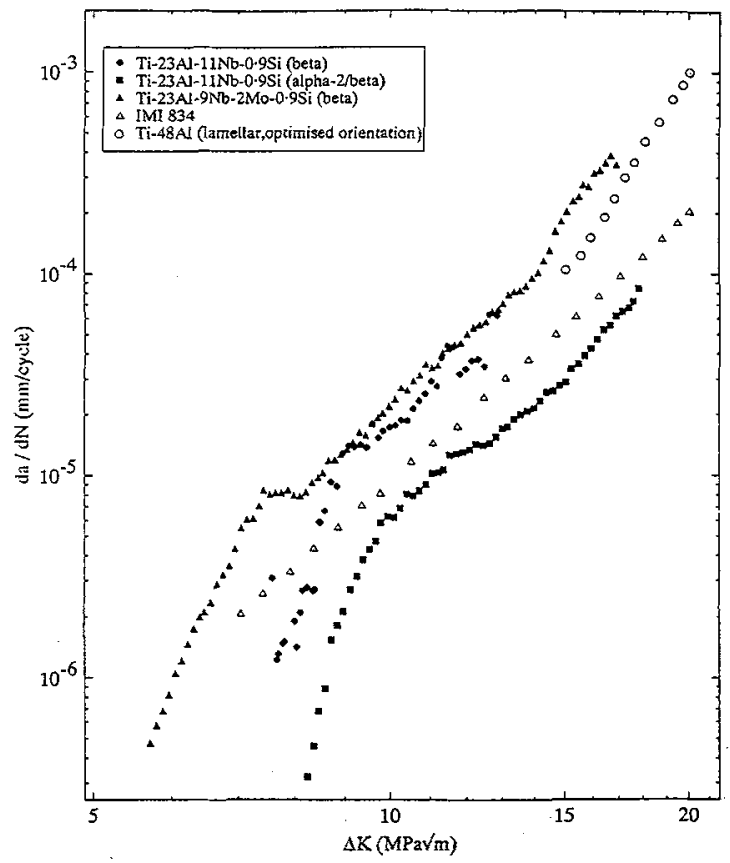

Figure 14. A comparison of fatigue crack growth resistance curves at room temperature. 